\title{
OLHARES DE GÊNERO E INTERSECCIONALIDADE NO ENSINO DE HISTÓRIA. REFLEXÕES SOBRE A HISTORICIZAÇÃO DA DIFERENÇA NOS PROCESSOS DE EDUCAÇÃO HISTÓRICA
}

\author{
Álvaro Ribeiro Regiani \\ Universidade Estadual de Goiás (UEG), Brasil \\ E-mail: alvaroregiani2@gmail.com \\ ORCID: https://orcid.org/0000-0003-0685-435x \\ Kenia Erica Gusmão Medeiros \\ Universidade Federal de Goiás (UFG), Brasil \\ E-mail: keniaerica.gm@gmail.com \\ ORCID: https://orcid.org/0000-0002-1364-9517
}

Data de recebimento: $14 / 02 / 2020$

Data de aprovação: 29/03/2020

DOI: $\underline{\text { https://doi.org/10.30612/frh.v22i39.12568 }}$

\begin{abstract}
Resumo: Há algumas décadas a proliferação de pesquisas históricas por perspectivas de gênero, classe, etnia, idade dentre outras condições sociais e posteriormente o entrecruzamento dessas categorias, aumentaram as possibilidades de interpretação e escrita do passado. O objetivo deste artigo é discutir as possibilidades e desafios presentes na educação histórica enquanto campo de entendimento e debate dos processos históricos que fundamentam a condição dessas categorias no presente e no cotidiano dos estudantes. A utilização da pluralização de passados, de narrativas históricas e de compreensões que desvelem identidades, representações e imposições do presente, como construções históricas, fazem parte da efetivação de uma educação histórica voltada para a cidadania plena. Nesse sentido, defendemos neste texto gênero e interseccionalidades como operadores fundamentais para o desenvolvimento da consciência histórica.
\end{abstract}

Palavras-chave: ensino; gênero; interseccionalidades; educação histórica; consciência histórica.

\section{Gender and intersectional in history's teaching. Reflections and notes about the importance of difference historicization in historical education processes}

\begin{abstract}
A few decades ago the proliferation of historical research from the perspective of gender, class, ethnicity, age, among other social conditions and later the intersection of these categories increased the possibilities of interpretation and writing of the past. This article aim's discuss the possibilities and challenges present in historical education as a field for understanding and debating the historical processes that underlie the condition of these categories in the present and in the daily lives of students. The use of the pluralization of pasts, historical's narratives and understandings that unveil identities, representations and impositions of the present, as historical constructions, are part of the realization of a historical
\end{abstract}


education focused on full citizenship. In this sense, we defend in this text gender and intersectionality as fundamental operators for the development of historical consciousness.

Keywords: Teaching; Gender; Intersectionality; Historical's education; Historical's consciousness.

\section{Género y interseccionales en la enseñanza de la historia. Reflexiones y notas sobre la importancia de historizar la diferencia en los procesos educativos históricos}

Resumen: Hace unas décadas, la proliferación de la investigación histórica desde la perspectiva de género, clase, etnia, edad, entre otras condiciones sociales, y más tarde la intersección de estas categorías, aumentó las posibilidades de interpretación y escritura del pasado. El objetivo de este artículo es discutir las posibilidades y desafíos presentes en la educación histórica como un campo para comprender y debatir los procesos históricos que subyacen a la condición de estas categorías en el presente y en la vida cotidiana de los estudiantes. El uso de la pluralización de pasados, narraciones históricas y entendimientos que revelan identidades, representaciones e imposiciones del presente, como construcciones históricas, son parte de la realización de una educación histórica centrada en la ciudadanía plena. En este sentido, defendemos en este texto el género y la interseccionalidad como operadores fundamentales para el desarrollo de la conciencia histórica.

Palabras clave: Enseñanza; Género; Interseccionalidad; Educación histórica; Conciencia histórica.

\section{Introdução}

A incorporação da história das mulheres e de uma história das relações de gênero na historiografia é recente. A difusão dessas pesquisas e a produção de conhecimento tendo como base essas perspectivas na educação histórica, ainda são desafios do ensino de história. Por especialmente no Brasil, mas também em outros países da América do Sul, a educação ter se tornado uma trincheira na qual ocorrem diversas batalhas de significação em torno dos debates de gênero. A História das Mulheres surgiu nos anos 60 e foi popularizada nas décadas seguintes, ela representou um marco no questionamento das posições hegemônicas escondidas por trás da suposta neutralidade do discurso histórico e da universalidade do sujeito masculino. A abertura desse campo, além de contribuir para a renovação e o adensamento da historiografia, propiciou também a formação da área conhecida como "Estudos de gênero". $\mathrm{Na}$ ciência histórica, as décadas de 80 e 90, foram importantes para a divulgação e assimilação de uma epistemologia de gênero, que se deu por meio de publicações e pesquisas. 
Como mencionado, atualmente os "Estudos de gênero" representam, nas escolas, um ponto de tensão que extrapola os interesses do bom desenvolvimento da cultura escolar.

Todavia, o gênero não opera sozinho enquanto categoria social e por isso, é preciso que cada vez mais, a opressão de gênero existente nas sociedades seja relacionada com opressões de raça e classe. Um caminho é a utilização da categoria de intersesccionalidade, que busca investigar longos processos, estruturas e interações entre diferentes práticas de dominação e exclusão. Sem esse entrecruzamento, o debate sobre as imposições e desigualdades em função do gênero exclui realidades e oculta diferenças em nome de uma reivindicação de igualdade que não considera a complexidade das opressões arraigadas nas sociedades contemporâneas. Numa dimensão intragênero mulheres e homens têm suas condições de feminilidade e masculinidade influenciadas por outras variantes sociais. $\mathrm{O}$ fator gênero se entrelaça numa rede de estruturas e discursos dos quais os indivíduos homens ou mulheres tomam parte. Ele mobiliza e é mobilizado por essas outras instâncias sociais e culturais.

A sistematização da noção de interseccionalidade foi uma iniciativa da feminista norte-americana Kimberlé Crenshaw em um artigo de 1989 intitulado "Desmarginalizando a intersecção de raça e sexo: uma crítica feminista negra da doutrina antidiscriminação, teoria feminista e políticas antirracistas". Não obstante, a importância de demarcações sobre o surgimento de conceitos, como o caso mencionado, ponderamos que elas fazem parte de contextos de produção e discursividades, são muitas vezes ecos de demandas e questões sociais do presente. Desse modo, não podemos deixar de citar os trabalhos anteriores das pesquisadoras brasileiras, Lélia Gonzales e Beatriz Nascimento, que já discutiam questões sobre o ser negro e a corporiedade envolvida nessas existências relacionando tais questões com aspectos históricos, espaciais e sociais. Uma via de interseccionalidade que passava pelo o que Lélia Gonzales chamou de "amefricanidade" e também pelas elaborações sobre o quilombismo realizadas por Beatriz Nascimento, ambas conceituações políticas e culturais muito próximas do que se entende hoje como interseccional.

A interseccionalidade se configura então numa organização de entendimentos sobre o entrecruzamento de diferentes estruturas de subordinação que mantém conexões com processos históricos, que envolvem categorias também distintas e que possuem desdobramentos que geram desequilíbrios e desigualdades sociais no presente. Ela faz referência a uma trama de cargas simbólicas de opressão que são socialmente articuladas, demarcando espaços de fala, de vivência, de trabalho, enfim, reforçando, renovando e 
sofisticando a interação dos modos de discriminação. Retomando a conceitualização de Crenshaw ela constitui:

A associação de sistemas múltiplos de subordinação tem sido descrita de vários modos: discriminação composta, cargas múltiplas, ou como dupla ou tripla discriminação. A interseccionalidade é uma conceituação do problema que busca capturar as consequências estruturais e dinâmicas da interação entre dois ou mais eixos da subordinação. Ela trata especificamente da forma pela qual o racismo, o patriarcalismo, a opressão de classe e outros sistemas discriminatórios criam desigualdades básicas que estruturam as posições relativas de mulheres, raças, etnias, classes e outras. Além disso, a interseccionalidade trata da forma como ações e políticas específicas geram opressões que fluem ao longo de tais eixos, constituindo aspectos dinâmicos ou ativos do desempoderamento (CRENSHAW, 2002, p. 177).

A própria problematização dos sentidos empenhados no termo "gênero" e nas demandas e sujeitos abarcados nos estudos dessas relações, necessita ser realizada nas pesquisas e no ensino de história. A complexificação das sociedades se relaciona diretamente com processos de compreensão, definição, representação e escrita de si. $\mathrm{Na}$ contemporaneidade os debates de gênero, assim como os movimentos feministas, deparam-se com identidades e narrativas diversas que clamam por representatividade e participação na criação nessas agendas. O reconhecimento e a consideração da interseccionalidade é uma dessas demandas.

Como o gênero está sendo definido é o que estamos questionando: que tipo de função está exercendo e para quem? As incertezas e indeterminações das categorias garantem que as respostas irão variar dependendo do contexto: histórico, político, cultural e temporal (SCOTT, 2020, p. 19).

Em síntese, além das desigualdades provocadas pelas imposições de gênero, existem nuances diferentes no interior da dimensão do gênero, ou seja, sobre o feminino e o masculino, recaem outras dimensões sociais, como etnia, classe, idade e todas essas categorias devem ser abordadas numa educação histórica que articule o conhecimento histórico e a promoção da cidadania no desenvolvimento da consciência histórica. Uma cidadania, na qual predomine a percepção do outro e da sua alteridade, não como ameaça, mas como diferença a ser conhecida e respeitada e ainda o reconhecimento de que classificações sejam elas de gênero, de classe, de orientação sexual, de faixa etária, ou de etnia, são resultados de construções históricas e sociais: 
Em diferentes medidas e de modos também distintos, ambas são problemáticas. A cidadania atrelada ao civismo cego e aos valores tradicionais não propicia a construção de atitudes de respeito e tolerância na cultura escolar, ao contrário, ajuda a promover e perpetuar exclusões, sendo ainda um entrave ao desenvolvimento da consciência histórica do aluno. Essa idealização pode formar alunos que acreditam que seus posicionamentos alinhados a valores conservadores os definam como merecedores de uma maior parcela de direitos, um selo de cidadão exemplar que na verdade, corresponderia a uma vivência de alienação perante a complexidade das sociedades contemporâneas (MEDEIROS; REGIANI, 2020, p. 483).

Em um livro de retomada e discussão de alguns conceitos importantes para a compreensão da obra de Jörn Rüsen, o historiador Arthur Alfaix argumentou que no contexto de orientação cultural, por meio da narrativa histórica o passado é "despresentificado", ou seja, é apresentado como tendo "passado" (ALFAIX, 2010, p. 20). Em outras palavras, a importância da narrativa histórica está também em sua capacidade e função de demonstrar algo como sendo passado. Essa despresentificação do passado que faz parte da experiência histórica deve compor o ensino de história. A educação histórica deve levar o aluno a uma aprendizagem histórica que identifique que o passado está inscrito no presente em permanências e ou em atualizações de tradições e de passados. Muitas dessas inscrições de passados no presente são positivas por seu valor simbólico e cultural, sendo representações de tempos e constituindo sentidos temporais para identidades presentes. Outras, mesmo que em discurso sejam defendidas como preservação de valores culturais, estão mais próximas uma concepção de história teleológica que insiste na legitimidade das origens e do passado, para a manutenção de desigualdades e exclusões. Tal concepção também opera em discursos de relativização ou banalização de eventos traumáticos, sua finalidade é a manutenção e a de uma ordem social estabelecida.

Por meio da compreensão de que o presente, mesmo repleto de vestígios e de resultados de processos históricos, constitui uma instância de temporalidade atravessada por outras questões e possibilidades, a aprendizagem histórica pode se aproximar de cidadania em profundidade. Nesse sentido, a concepção de gênero e das tantas interseccionalidades de raízes históricas e consequências sociais que fazem com que mulheres e homens vivenciem tais ontologias de formas muito distintas em função dessas mesmas condições, são instrumentos fundamentais para a educação histórica. A constituição de sentidos temporais é assim, uma tarefa da educação histórica para a formação de uma consciência histórica que capacite indivíduos para a vivência da alteridade que se atualiza em cada presente. 
Mas para que se efetive essa constituição de sentidos, é preciso que se reconheça que os conteúdos curriculares da disciplina de história são alvo de embates e conflitos por inclusão e significação. É de suma importância que os currículos contemplem as questões de gênero e de outras opressões, das quais tratam os estudos interseccionais. Nos últimos anos foram deflagradas perdas significativas em documentos curriculares, no tocante aos debates de gênero e também às diferenças e desigualdades sociais presentes na sociedade brasileira. Exatamente por esse motivo, torna-se fundamental, uma prática docente que busque em alguma medida subverter no cotidiano da sala de aula, as ausências que permeiam o currículo formal da História. A ação docente com vistas a transformação cultural e social de desigualdades é parte indissociável para a configuração de uma aprendizagem histórica que ressoe ecos de cidadania.

Pelos resultados das inúmeras investigações de cariz qualitativo, com análise indutiva sobre dados obtidos em tarefas que procuram ser, simultaneamente, desafiantes e adequadas aos sujeitos que nelas participam, ousa-se afirmar que os objetivos do ensino da História podem e devem constituir uma ponte gradual, e não um fosso, entre o que os alunos aprendem e o que os historiadores e filósofos da História pensam e produzem. Só assim a educação histórica estará apta a responder às exigências do pensamento científico numa perspectiva de desenvolvimento humano sustentado (BARCA, 2012, p. 38).

Por tudo o que foi até aqui exposto, defendemos que a urgência de que sejam produzidos trabalhos que investiguem a construção de uma discursividade sobre o gênero nas sociedades contemporâneas e que orientem as práticas de ensino e a as possibilidades de aprendizagem histórica tendo como premissa, um ensino de história que contemple o gênero como construção social de longa duração com impactos em vários aspectos da vida humana.

\section{Possibilidades e desafios dos debates sobre relações de gênero e interseccionalidade na Educação histórica}

Os estudos de gênero e interseccionalidade fazem parte da pluralização dos objetos e métodos do conhecimento histórico. A existência e a fecundidade dessa pluralização evidencia o impedimento de que se pense em uma teoria final e um método único para todos os objetos e fontes dos quais se ocupa a história hoje. No entanto, o que Rüsen denomina como "matriz disciplinar" confere unidade aos distintos modos incluídos atualmente nas possibilidades do fazer historiográfico. Tal matriz funciona como uma rede de princípios 
comuns aos estudos históricos e suas variações (ALFAIX, 2010, p. 10). Essa matriz teria em sua constituição as questões essenciais presentes na produção da história profissional, sendo assim, uma proposta de um acordo regido por princípios científicos e éticos que visam abarcar as mais diferentes correntes teóricas.

A constituição de sentido sobre o tempo que ocorre nas experiências vividas na dimensão cotidiana faz parte das maneiras pelas quais as pessoas interpretam e transformam o mundo. Ou seja, a percepção, a ação, a vivência e a transformação do mundo social dependem diretamente da interpretação que esses indivíduos fazem do tempo. Nas instituições educacionais, as constituições de sentido temporal trabalhadas no ensino de história, nem sempre tem chegado a uma desconstrução satisfatória de naturalizações de imposições de gênero e de outras desigualdades sociais relacionadas à etnia, classe, idade, entre outras variáveis. Tais concepções continuam desfrutando de um status do "sempre foi assim", de onde surge a dedução de que, portanto, não há o que se possa ou deva fazer objetivando transformações, porque certas coisas sempre serão assim.

Essa condição tem muito a ver com processos de socialização que se iniciam ainda na primeira infância. É comum que os valores familiares, muitas vezes de ordem tradicional e conservadora sejam repassados às crianças como sentidos morais inalienáveis, inclusive sob penas sociais e religiosas. O sentido de tempo que muitos estudantes trazem para a aula de história é o de uma dimensão na qual as coisas presentes sempre existiram e por isso, o mundo é e deve permanecer assim, podendo ser avaliados em um estágio tradicional de consciência histórica. Há nessa conformação, uma nítida questão de estabilidade. Por isso, qualquer desconstrução, não obstante sua importância e a pertinência acarretam para muitos alunos um abalo nas suas visões de mundo, na estabilidade de sentidos que conferem ao tempo e para a lógica social da vida que conhecem.

Esse abalo pode ser mais ou menos intenso de acordo com inumeráveis variáveis culturais e relações de pertencimento de cada estudante. Ele pode representar um custo social no qual o estudante pode sentir que seu mundo e suas compreensões não tenham valores, exatamente por não serem atuais. Por outro lado, esse abalo, pode representar exatamente a abertura para uma autocrítica sobre os sentidos de tempo e de sociedade que esse aluno traz consigo. Nesse caso, quanto melhor for a experiência estética vivida nessa aula, maiores as chances de uma aprendizagem histórica que alavanque uma mudança de nível de consciência histórica sobre determinado assunto. 
Sem essa força estética com a qual a subjetividade dos sujeitos é interpelada, a História jamais alcança influência sobre as disposições mentais profundas do agir. É nesse nível estético que as interpretações do passado atuam sobre os alunos de modo a não só reinterpretarem o presente, mas também a se sentirem motivados para o agir. É nesse momento que a consciência histórica atua de modo efetivo, com uma interpretação do passado que produz orientação temporal para o agir humano em sua vida prática (SADDI, 2016, p. 121).

Para um direcionamento desse movimento que ocorre dentro do ensino, uma ação pedagógica de escuta é fundamental. Esta é também uma estratégia didática para que se possa avaliar o nível de consciência histórica dos estudantes envolvidos na aprendizagem. A escuta das protonarrativas dos alunos, ou seja, das concepções históricas que ele já possui sobre determinados temas, constitui um valor inestimável não somente para os processos avaliativos que devem estar presentes nos programas, a fim de garantir o direito à aprendizagem para todos, mas também para que docentes desenvolvam abordagens históricas que considerem a cultura histórica com a qual esses estudantes se vinculam. Nessa escuta, mesmo sendo ela um diálogo entre diferentes, não por uma suposta hierarquia entre o que ensina e o que aprende, mas pela assimetria dos locais de fala e da forma de relação com o passado.

Nas tramas da cultura escolar, as questões de gênero, sexualidade e interseccionalidade, surgem em cotidianos atravessados por presenças que desvelam diferenças. Apesar da diversidade de sujeitos e narrativas que compõem os ambientes escolares, ainda são insuficientes no nível curricular e pedagógico, as políticas para a visibilidade dessa multiplicidade de identidades que se entrecruzam nos cotidianos instaurados. $\mathrm{O}$ ensino de história pode e deve ser um campo de conhecimento e pesquisa que promova entendimentos sobre processos históricos que são produtores de diferenças sociais e culturais visíveis no presente.

Todo conhecimento histórico pode ser trabalhado por uma perspectiva de gênero. Nesse sentido, é importante, ressaltar que a categoria de gênero, não deve ser confundida ou simplificada como sinônimo para o feminino. A força do gênero reside exatamente na possibilidade que ele oferece para a percepção e a discussão sobre os processos históricos que organizam, delimitam e impõem definições sociais para o feminino e para o masculino, a partir da percepção da diferença sexual. Assim, tratar o conhecimento histórico a partir da categoria de gênero significa antes de qualquer coisa, considerar aspectos fundamentais da ação humana nas sociedades ao longo do tempo. 
O ensino de história deve oferecer o saber histórico acumulado em pesquisas da área, por meio de processos didáticos e pedagógicos que envolvam experiências com vinculações à esfera do cotidiano. Quando o aluno percebe que a desconstrução de uma noção sobre o tempo, sobre uma estrutura social ou sobre um contexto histórico, possui vinculações com situações por ele já presenciadas ou vividas no cotidiano, essa não lhe interpela como agressão, ao contrário, produz uma janela de oportunidades de um despertar de interesses por meio de um sentimento de cumplicidade para com a professora ou o professor que a propõe.

Muitos alunos quando ouvem em aulas de história, mega conceitos como "socialismo"; "capitalismo"; "machismo"; "feminismo"; "racismo"; não atribuem para esses sentidos a mesma carga semântica empenhada pelo professor. Muitos chegam a noções nebulosas, limitadas ou distorcidas sobre esses termos. Uma possibilidade interessante é a inversão da apresentação de conceitos, primeiramente sendo discutidas situações que o aluno possa ter observado ou vivido no seu cotidiano, relacionadas a uma determinada noção histórica e ou social, para que depois se atribuam nomes a essas percepções e experiências. Não se trata de negar a força de representação histórica e social desses termos, mas de aproximar o estudante, para que o mesmo se aproprie dessas noções, a partir da compreensão dos processos históricos dos quais elas se desdobram e da identificação das mesmas em situações do seu cotidiano.

Por exemplo, a explanação de situações históricas de discriminação ou violência em função do gênero. Durante a aula podem ser utilizadas fontes diversas como jornais, fotografias, textos historiográficos dentre outras tantas possibilidades. Quando a apresentação de uma situação de desigualdade e injustiça social em função de uma condição ontológica precede o ato de nominar a resistência a essa mesma ocorrência, se ganha no aluno, um cúmplice de uma narrativa que merece um desfecho de reparação. Mas esse sentido de reparação não se encontra no passado inalienável, mas exatamente no presente por meio do conhecimento sobre o que passou e mais, na transformação cultural que a orientação no tempo por meio de uma constituição de sentido profunda pode provocar. O que se verifica é que muitos alunos demonstram ter grande parte de seus pensamentos históricos ancorados ainda no nível de base tradicional, são contra termos como o "feminismo", mas são favoráveis à igualdade entre homens e mulheres na sociedade em muitos aspectos da vida social.

$\mathrm{O}$ trabalho com o gênero e com categorias sociais que marcam lugares decorrentes de processos históricos na sociedade, apesar de poder ser realizado por meio de projetos, palestras, oficinas, ou seja, em momentos que de algum modo suspendem o cotidiano da sala 
de aula, precisa também ser incorporado no dia-a-dia da ação pedagógica e inserido no currículo real. Momentos como celebrações de datas, recebimento de pessoas com conhecimento na área para falas e eventos afins são bem-vindos, mas algumas ponderações precisam ser feitas. Não devemos auxiliar na promoção de uma aprendizagem que considere que os discursos sobre desigualdades, sejam quais forem, mas nesse caso, especificamente as de gênero e suas relações de interseccionalidades, como um ponto fora da história, como um adendo sobre o qual em algumas oportunidades alguém aparece para discursar. Mesmo que esses momentos consigam incentivar reflexões, se o trabalho não estiver presente no cotidiano e sendo uma das perspectivas pelas quais os conteúdos da história disciplina são apresentados e discutidos, gênero, classe e etnia tornam-se notas de rodapé na educação histórica.

É evidente que o conhecimento histórico é o instrumento pelo qual a despresentificação do passado pode ser realizada no ensino, ainda sim, é preciso observar que limitar a educação histórica a uma reprodução desse saber não permite a realização de uma educação histórica plena, mas sim da execução de uma assimilação de contextos com os quais os estudantes não conseguem sequer estabelecerem processos de metacognição, ou seja, de como os alunos relacionam os novos conhecimentos aos que já possuem e a partir de então formulam sentidos para a vida prática ${ }^{1}$. A compreensão da didática da história é fundamental para a efetivação de uma educação histórica conceituada de forma que visa a garantia de uma aprendizagem significativa e por perspectivas plurais.

A didática da história não se ocupa apenas das competências que devem ser adquiridas mediante a aprendizagem histórica, mas também dos processos mentais de constituição histórica de sentido inseridos em um movimento de aprendizagem (RÜSEN, 2015, p. 252). Esses processos mentais não podem ter como finalidade somente a aquisição de definições históricas e interpretações do passado, mas também da capacidade de se perceber nessas elaborações e sínteses, os percursos pelos quais alteridades vistas e vividas hoje se desenvolveram no tempo. Nesse sentido, as diferenças que surgem das condições de gênero, origem, classe, orientação sexual, idade, corpo, dentre tantas outras possíveis, devem ser apresentadas e discutidas como construções sociais e históricas. Em outras palavras, ensinar história é também historicizar as diferenças.

A pesquisa, a escrita e o ensino de história devem ser compreendidos e realizados como compromissos político-pedagógicos com a transformação da sociedade por meio da constituição de sentidos de tempo, realizada por meio da história ciência. Assim, essas 
dimensões do pensamento histórico, são impregnadas de sentidos práticos, de utilidade social e de relações estabelecidas entre pesquisadores e sociedade. No ensino as teorias da história, incluindo a epistemologia de gênero, podem ser aplicadas, desse modo, professoras e professores podem obter respostas sobre validações e possíveis melhorias nesses referenciais.

O ensino constitui uma das oportunidades de diálogo, assimétrico, pois são locais de fala diferentes, mas real, entre historiadores e suas comunidades, abrindo caminho assim para o aprofundamento da cultura histórica. A discussão da historiadora Diva Muniz transcrita abaixo, oferece também entendimentos possíveis para o ensino de história por meio da perspectiva de gênero e suas possíveis interseccionalidades:

Finalizo, ressaltando que pesquisar, escrever e ensinar história é um ato político. Escrever a História das Mulheres é um ato explicitamente político, posicionado, comprometido com o projeto de mudanças das e nas relações entre mulheres e homens. [...]. É um ato que nos exige pensar e praticar a história insistindo em afirmar e lutar para assegurar aquilo que toda e qualquer pessoa tem de mais valioso, sua dimensão humana, sua humanidade (MUNIZ, 2020, p. 38).

Mais que uma escolha teórica metodológica, o ensino de história que desvela a historicidade presente nas diferenças, nas assimetrias e desigualdades sociais visíveis em corpos, afetividades, narrativas, representações e lutas, é uma necessidade para que o presente não permaneça comprometido por ausências de alguns passados que não se tornaram narrativas. A elaboração historiográfica de passados plurais permite a compreensão da diversidade de sujeitos, identidades e condições do presente. Não obstante, as múltiplas formas de divulgação e publicização existentes dessas narrativas, cabe ao ensino de história a missão de produzir tendo como referência esses saberes acumulados, uma orientação temporal nascida no processo de educação histórica.

\section{Ensino em prática: Temas do conhecimento histórico a partir de uma perspectiva de gênero e interseccionalidades}

Como já discutido nesse texto, todo o conhecimento histórico pode ser ensinado com a consideração do ponto de vista dos estudos de gênero e interseccionalidade, exatamente por que contextos e eventos históricos são atravessados e organizados em função dessas 
desigualdades e percepções. As próprias construções narrativas sobre esses passados são assimétricas no tocante a essas categorias, sendo a história e seu ensino, ainda tomadas por perspectivas e protagonismos do sujeito masculino branco. Não trataremos aqui de exemplos possíveis para cada tema o período histórico, mas discutiremos um número de exemplos suficientes, inclusive em diversidade, para avançarmos em um debate que levante questionamentos e proponha orientações para professores e estudantes de história que desejem aprofundar a utilização das categorias de gênero e intersesccionalidade em suas aulas. $\mathrm{Na}$ escolha desses exemplos, estamos tentando compor uma seleção que represente um pouco da pluralidade temática de boa parte dos currículos formais de história no Brasil. Partiremos da concepção de que a historicização dessa construção social que envolve a percepção das diferenças sexuais, deve ser apresentada em análises sobre o corpo, comportamento, narrativas e representações de si, bem como de contextos e eventos políticos e sociais do passado.

Começando pelo ensino de história antiga, há uma perda de sentidos importantes quando o universal masculino elimina a existência de mulheres importantes para as culturas estabelecidas nessa época. Esse universal masculino contribui para que mulheres como a faraó Hatshepsut ou a matemática e filósofa Hipátia, pouco sejam lembradas no ensino de história. Os faraós e $o s$ filósofos, generalizam os livros didáticos. Além dos ganhos com essa história das mulheres, discussões de gênero também são fundamentais para a compreensão da própria predominância do masculino no mundo egípcio e helenístico, por exemplo, na percepção das noções de sexualidade dessas sociedades. Na antiguidade os significados de ser homem, em algumas questões, diferiam muito dos ideais de masculinidade que podem ser observados hoje. Essa discussão é um exemplo de uso da categoria de gênero no ensino, extrapolando inclusive a ideia equivocada de que a mesma só trata do feminino.

Outras possibilidades são discutidas no livro "Novos temas nas aulas de história", de Carla Pinsky (2018). Dentre vários exemplos sobre conteúdos curriculares de história a partir de um olhar de gênero, a autora destaca as concepções dos filósofos iluministas durante o século das "luzes", sobre a superioridade dos homens sobre as mulheres. Pensar o gênero ajuda nesse caso, inclusive na percepção de como os discursos filosóficos estão em diálogo direto com a cultura de um tempo. Em outro tópico, a historiadora ressalta ainda como o nazismo dialoga com o ideal de uma superioridade racial simbolizada pelo homem viril. Acrescentamos que no caso do nazismo a discussão sobre a origem, deve entrar como outro viés de subordinação que pode estar em paralelo com o gênero no caso das vítimas mulheres. 
Desse modo, Pinsky cria um percurso de ideias para a incorporação do gênero nas aulas de história, passando por vários contextos e eventos.

Em texto que versa sobre a violência nos livros didáticos de história, Susane R. de Olveira (2020) discute sobre os estupros coletivos na Idade Média e como estes consistiam uma forma de afirmação da virilidade. A autora problematizou como são tratadas essas questões a partir do manual didático, que tipo de representação de masculinidade elas trazem e como se relacionam com a violência no presente. O texto aponta discussões extremamente pertinentes para a formação docente em história, consistindo em uma proposta para discussões de gênero que podem ser feitas sobre os livros didáticos e sobre as representações neles contidas. Um debate sobre o tema, chegando ao presente, como classe social e idade podem aumentar a vulnerabilidade das mulheres em relação aos atos de violência sexual, estabelecendo ainda uma comparação com as diferenciações sociais da época a qual se refere o texto.

O tratamento da violência sexual como uma parte onipresente da história, dificulta a capacidade de nossas/os alunas/os questionarem por que esses eventos ocorreram em tempos e lugares específicos, incluindo o presente. Existe o perigo de assumir uma tendência masculina inata de cometer violência sexual, ao invés de compreender a historicidade desse comportamento, bem como de seus significados e modos de funcionamento na vida social. A naturalização do desejo sexual masculino desenfreado se reflete na indiferença em relação à violência sexual na história. Essa suposição nociva tende a apagar os fatores sociais que tornam esse tipo de violência tão predominante (OLIVEIRA, 2020, p. 35).

Trazendo mais um exemplo de conteúdo do ensino de história, podemos abordar a história da conquista que é tantas vezes ensinada tendo Cortez como personagem central e sem nenhuma referência à Malinche, personagem sobre a qual paira uma polissemia de sentidos e interpretações, mas que de toda forma é fundamental para a compreensão da conquista. Sobre Malinche viveu a condição de mulher ameríndia e apesar da escassez de fontes sobre a mesma, esse cruzamento interseccional pode auxiliar na compreensão sobre a participação dessa mulher na conquista espanhola.

Outro exemplo está no ensino sobre a Revolução Francesa ainda em dívida com Olympe de Gouges, atriz, escritora e de opinião contrária a escravidão dos negros, ela escreveu a "Declaração dos direitos da mulher e da cidadã em 1791. Com artigos precisos a declaração é bastante lembrada pela convocação: "Mulher, acorda; o chamado da razão se faz ouvir em todo o universo; reconhece teus direitos". Também é bastante citado o décimo 
artigo: "A mulher tem o direito de subir no cadafalso, ela deve ter o direito de subir na tribuna" (GOUGES, 1791 apud PERROT, 1998). A escritora subiu no cadafalso em 1793, ainda não recebeu as glórias, a mesma atenção dedicada a Robespierre no ensino de história.

Sobre o ensino de história do Brasil, ainda é preciso aprofundar as questões sobre a escravização de negros e indígenas e de como o fator gênero pode deslindar lugares de dor, sujeição e resistência que são parte de contextos ainda mais traumáticos. As leis 10.639 de 2003 e 10.645 de 2008 foram importantes instrumentos para uma maior pluralização de passados e sujeitos no ensino de história, mas especialmente a história das mulheres negras e indígenas, precisa ganhar contornos mais nítidos na educação histórica. A historiografia de gênero atual tem avançado na produção de conhecimentos sobre essas mulheres e é importante que a educação histórica ressignifique esses saberes para a cultura escolar e também produza suas interpretações sobre a opressão e a resistência desses grupos na história do Brasil durante séculos.

A necessidade de tornar fazer desses passados conteúdos curriculares obrigatórios, já fornece indícios sobre a dimensão de exclusão dessas identidades na história ensinada. Apesar da importância dessas legislações, o caminho da produção histórica relacionada a esses temas no ensino, ainda está repleto de percalços. E nesse sentido, abordar as mulheres negras e indígenas enquanto sujeitas históricas silenciadas e marginalizadas, mesmo na historiografia, requer o uso da categoria de interseccionalidade.

$\mathrm{Na}$ contramão de alguns avanços, nos últimos anos escolas tornaram-se verdadeiros alvos de ataque de discursos conservadores e propagadores de pânico moral, em função da existência de uma suposta "ideologia de gênero" sendo ensinada nas instituições brasileiras. A pergunta que fica é: a quem interessa o silenciamento e a invisibilidade das diferenças na escola? Os interessados não podem ser resumidos a apenas um grupo. Mesmo com a aliança formada pelo discurso conservador, pelo religioso e pelo neoliberal, deflagrada no Brasil atual, existem assimetrias de objetivos e interesses no que se refere à interferência no ensino, proposta por esses grupos.

Precisamos considerar que existem diferenças, realçá-las dentro desses discursos, para que sejam identificados os sujeitos preocupados com custos sociais e valores morais e os que estão realizando um investimento em busca de manutenção de poder e desigualdades. Essa identificação é fundamental para a construção de um diálogo que pode e deve ser iniciado no ensino e estendido a toda a comunidade escolar. A dimensão adquirida pela discussão em torno do gênero no ensino é inclusive um indício da percepção de agentes dominadores, 
especialmente políticos, da força de mobilização e transformação que constituem o ensino de ciências humanas e da potência educadora dos diálogos sobre os determinismos de gênero.

É preciso que as próprias noções de gênero e feminismo sejam atualizadas e ressignificadas tanto no ensino quanto na cultura escolar. Essas noções precisam abarcar as diferentes possibilidades de configuração das feminilidades e masculinidades que existem na cultura escolar. É interessante, no entanto, que anterior a apresentações e revisões de conceitos tão complexos, sejam realizadas incursões narrativas que demonstrem por meio de exemplos, a formação histórica dessas abstrações teóricas por meio de conflitos e lutas e suas aplicabilidades no presente.

\section{Considerações finais}

O desenvolvimento da consciência histórica ocorre pelo aprofundamento do senso crítico, que opera um movimento de revisão acerca do conhecimento que se tinha sobre determinado assunto, incorporando-se assim novas perspectivas sobre esse mesmo tema. É na dimensão de desenvolvimento da consciência histórica operada no ensino formal, com a consideração de diferentes sujeitos, identidades e narrativas muitas vezes derivadas de sobreposições de processos históricos, que se encontra a abertura para a mudança de estágio. Apesar dessa teoria conceber uma progressão do pensamento entre estágios, ela não constitui uma defesa de um tipo de adaptação ao mundo caracterizada por uma evolução em sentidos biológicos. O desenvolvimento da consciência histórica é um exercício de cidadania, por que ele permite justamente, por meio da historicização de diferenças, a formação da empatia para com os outros e o desejo e transformação do mundo.

Nesse sentido, para que a educação histórica possa constituir um meio de transformação social, ela precisa conceber e retratar a pluralidade de passados que compõem as condições e identidades visíveis e invisibilizadas no presente. Apesar de possível e necessária, a mediação do historiador na cultura histórica, o alcance do seu trabalho na formação da consciência histórica pode produzir, mesmo que a longo prazo um impacto mais significativo.

Sugerimos então, gênero e interseccionalidade como operadores didáticos do ensino de história para o desenvolvimento dessa consciência. As epistemologias que entrecruzam gênero, classe, etnia, e as tantas pedagogias interculturais são meios de tornar o conhecimento histórico uma ferramenta de transformação social que atravessa a sociedade por meio de 
discursos e práticas que estabelecem pontes entre a academia e a escola. Há um perigo em não reconhecer as especificidades da opressão (BIDASECA, 2018, p. 300), identificá-las, tornálas visíveis é um dos caminhos para uma educação que seja prática transformadora e humanizadora, para um ensino que seja feminista e antirracista. Tomando como verdadeira a afirmação de que a dimensão mais significativa da orientação histórica forma-se na conexão íntima entre experiência do passado e identidades atuais (ALFAIX, 2010, p. 19), defendemos que a educação histórica é eficaz na constituição de um sentido de cidadania plena e solidária, quando fundamentada em sentidos temporais que desvelam temporalidades sobrepostas no mundo cultural, propiciando orientações para o agir.

\section{Referências}

ALFAIX, Arthur. A teoria da história de Jorn Rusen: uma introdução. Goiânia: Editora UFG, 2010.

BARCA, Isabel. Ideias chave para uma educação histórica: em busca de (inter) identidades. História Revista. Goiânia, v. 17, n. 1, p. 37-51, jan./jun. 2012. Disponível em: https://www.revistas.ufg.br/historia/article/view/21683/12756. Acesso em: 04 jun. 2020.

BIDASECA, Karina. Nas trilhas do afrofeminismo: pedagogias feministas decoloniais para uma crítica anticolonial, atipatriarcal, antirracista, radicalmente livre. In: LOPES, Casimiro Alice; OLIVEIRA, Anna Luísa A. R. Martins; OLIVEIRA, Gustavo Gilson de Sousa (org.). Os gêneros da escola e o impossível silenciamento da diferença no currículo. Recife: Ed. UFPE, 2018.

CRENSHAW, Kimberlé. Documento para o encontro de especialistas em aspectos da discriminação racial relativos ao gênero. Revista Estudos Feministas. Florianópolis, ano 10, v. 1, 2002. Disponível em: http://www.scielo.br/pdf/ref/v10n1/11636.pdf. Acesso em: 05 jun. 2020.

MEDEIROS, Kenia Gusmão; REGIANI, Álvaro Ribeiro. O palimpsesto da cidadania e a educação histórica: reflexões sobre ensino e aprendizagem de história. In: BUENO, André; CREMA, Everton; MARTÍN, Nilson Javier (Orgs.) Ensino e aprendizagem histórica. 1. ed. Rio de Janeiro: Sobre Ontens; UNESPAR, 2020. Disponível em: https://www.academia.edu/43267431/Ensino e Aprendizagem_Hist $\%$ C3\%B3rica. Acesso em: 11 jun. 2020.

MUNIZ, Diva do Couto Gontijo. Mulheres, gênero e História: a constituição de uma área de estudos. In: SOARES, Ana Carolina Eiras Coelho; ZARBATO, Jaqueline Ap. M. (org.). História das mulheres e das relações de gênero no Centro Oeste: trajetórias e desafios. Campo Grande, MS: Life Editora, 2020.

OLIVEIRA, Susane Rodrigues de. Memórias de violência sexual nos livros didáticos de história. In: BUENO, André; ESTACHESKI, Dulceli T.; ZARBATO, Jaqueline (org.). Ensino de História e estudos de gênero. 1. ed. Rio de Janeiro; Nova Andradina: Sobre Ontens; UFMS, 2020. 
PERROT, Michelle. Mulheres públicas. São Paulo: Editora fundação UNESP, 1998.

PINSKY, Carla Bassanezi. Gênero. In: PINSKY, Carla Bassanezi (org.). Novos temas nas aulas de História. São Paulo: Contexto, 2016.

RÜSEN, Jorn. Teoria da História: uma teoria da História como ciência. Curitiba: Editora UFPR, 2015.

SADDI, Rafael. O estado de suspensão na aprendizagem histórica: a força estética do conhecimento histórico na instauração de um movimento sublime de consciência histórica. Revista História Hoje, São Paulo, v. 5, n. 9, p. 113-130, jun. 2016.

SCHMIDT, Maria Auxiliadora. Consciência histórica e aprendizagem: teoria e pesquisa da educação histórica. In: ROCHA, Helenice; MAGALHÃES, Marcelo; GONTIJO, Rebeca (org.). O ensino de história em questão: cultura histórica, usos do passado. Rio de Janeiro: FGV Editora, 2015.

SCOTT, Joan W. Gênero e as políticas da História: trinta anos depois. In: SOARES, Ana Carolina Eiras Coelho; ZARBATO, Jaqueline Ap. M. (org.). História das mulheres e das relações de gênero no Centro Oeste: trajetórias e desafios. Campo Grande, MS: Life Editora, 2020. 